\title{
The Implementation of CBT to Reduce Hyperactive Behaviors among Adolescents with ADHD
}

\author{
https://doi.org/10.3991/ijoe.v17i12.26531 \\ Khofidotur Rofiah ${ }^{1,2(\bowtie)}$, Joanna Kossewska1 ${ }^{1}$ Muhammad Nurul Ashar ${ }^{2}$ \\ ${ }^{1}$ Uniwersytet Pedagogiczny im. Komisji Edukacji Narodowej w Krakowie, Kraków, Poland \\ ${ }^{2}$ Universitas Negeri Surabaya, Surabaya, Indonesia \\ khofidotur.rofiah@doktorant.up.krakow.pl
}

\begin{abstract}
Adolescents with ADHD need serious handling to reduce their hyperactive Behavior. One strategy that is alleged to reduce this behavior is by implementing Cognitive Behavior Therapy (CBT). The purpose of this study was to determine the effect of the implementation of CBT and to analyze the effectiveness of CBT in reducing hyperactive behavior of adolescents with ADHD in Inclusive Junior High Schools. The implementation of this research used a pre-experimental research design with the One Group Pre-Test Post-Test research design by using the Vanderbilt ADHD Rating Scale behavior check instrument which is adopted by considering Indonesian language and culture. The subjects in this study were 3 adolescents with ADHD who had a level of activity representing the mild, moderate, and severe levels. The time used was 5 meeting sessions with a time allocation of $2 \times 30$ minutes for each meeting. The results showed that there is an effect of the implementation of CBT in reducing the hyperactive behavior of adolescents with ADHD at Inclusive Junior High School.
\end{abstract}

Keywords-young people with ADHD, cognitive behavior therapy, hyperactive behavior

\section{Introduction}

Adolescence is a developmental transition period between childhood and adulthood that generally begins at the age of 10 or 11 years and ends in the late adolescents or early twenty years ([1], [2], [3]). At this time, adolescents experience the development of all aspects, both physical, psychosocial, and cognitive. In the process of development, adolescents experience many challenges that come from outside themselves ([4], [5], [6]). This also occurs in adolescents with the condition who have problems and limitations, among them is a teenager with concentration problems and hyperactivity or Attention Deficit Hyperactive Disorder (ADHD) ([7], [8]).

Attention Deficit Hyperactive Disorder (ADHD) is a recognized and distinct medical disorder that tends to be hereditary ([9], [10]). Generally, there are three types of behavior associated with the disorder, namely: a lack of noticing (inattentiveness) or easily 
distracted (distractibility/hyperactivity), and the attitude of impulsive (impulsiveness) ([11], [12]). Although previously thought to be a neurological syndrome that occurs in childhood, it is now recognized that the majority of individuals diagnosed with ADHD will continue in adolescence and adulthood ([13]). The symptoms in adolescents with ADHD are marked by always "wanting to go", difficult to follow, never being able to stay still, wobbling, tapping fingers or toes, swinging legs, twirling, rising down, usually doing several things at once and can never sit still ([14], [15]).

Increasingly, the increasing number of children diagnosed with ADHD is generally accompanied by learning difficulties and other emotional-behavioral problems. In the studies that have been conducted the figures from different surveys in different cities and countries range from $5 \%$ to $22 \%$. Experts suggest the prevalence of ADHD or ADHD in school children ranges from 3\%-10\% ([16]), and 35-50\% of ADHD cases can progress to adolescence. In the UK, the National Institute for Clinical Excellence estimates that $1 \%$ of all children (approximately 69,000 children aged 6 to 16 ) meet the criteria for the most severe ADHD. The figures for all types of ADHD in the UK are very high, around 5\%, namely 365,000 children aged $6-16$ years. In the United States experts have an agreement that the prevalence of ADHD is 3\%-5\% in the pediatric population. A study on the prevalence of ADHD in Canada shows the results are $9 \%$ in boys and $3.3 \%$ in girls ([17]).

There is no definite national data on the prevalence of ADHD in Indonesia because not many studies have been conducted. However, it was found in a previous study by Anak that the prevalence of ADHD was $4.2 \%$. Data obtained from the Center for the Study and Observation of Growth in the period 1992-1998 showed $17.68 \%$ of the patients are children who have an attention disorder with or without hyperactivity and approximately seven out of ten children with ADHD will continue to display symptoms in adolescence ([18]). Some researchers have found that ADHD symptoms persist in some adolescents, ranging from $31 \%$ to $71 \%$, although it is reported that only about $8 \%$ of symptoms meet ADHD criteria in adolescence. Other literature states $15 \%-20 \%$ of ADHD persists until adolescence and $65 \%$ of them experience problems in academia and work ([19], [20]).

Adolescents with ADHD experienced difficulties in the field of academics and the persistence of social skills problems ([9], [21], [22]). More than one-third of adolescents with ADHD eventually drop out of school ([23], [24]). When one considers the foregoing facts, the prognosis for adolescents with ADHD is not very promising in most cases. More than half of individuals with ADHD at child age will continue to experience symptoms of impulsivity, inattentive, and hyperactivity until he becomes an adult ([25]). Only an estimated $20 \%$ to $35 \%$ of children with ADHD will be intact as adults ([26]). Recently, ADHD at the age of adolescents has been an attractive area for physicians, researchers, and others ([27]).

Adolescents with ADHD, need attention and treatment following individual characteristics and their development period. The characteristics of adolescents with ADHD are as follows:

Adolescents with ADHD have core disorders since childhood, such as distractibility, disorganization, difficulties with follow-up tasks, and impulsivity that prevent them from learning or using skills to overcome the problem that is effective to deal with duties basic life tasks (e.g., work, school, and relationships). Lack of skill to overcome 
the problem of effectiveness over time leads to the experience of repeated failure and an increase in achievement are low. This leads to an inability to manage the symptoms and continues to experience a functional decline.

As a result of chronic failure, Adolescents with ADHD received a lot of negative feedback from some parents, partners, teachers, and peers, which led to the emergence of thoughts and feelings that are negative ([28]-[31]). Negative feelings can result in avoiding coping with the fear of failure and lead to comorbid disorders such as depression or anxiety.

Adolescents with ADHD often display immature emotions compared to their peers. They will often do better when interacting with younger children or in an environment where adolescents tolerate immature behavior ([32]). Adolescents will be easily frustrated and have a "short fuse" with sudden emotional outbursts. Cognitive function problems are increasing in adolescents with ADHD ([33], [34]).

A preliminary study conducted at Inclusive Junior High School in Indonesia found several hyperactive children. Some of the teachers who handled them stated that the behavior that appeared in their students disrupted the teaching and learning process because some hyperactive students liked to disturb and even hurt their friends around them.

Recently, several researchers have shown that Cognitive-behavior Therapy (CBT) for adolescents with ADHD can be effective with or without medication ([35]). CBT believes that cognitive processes such as thoughts, interpretations, perceptions, and beliefs influence individual responses, behavior, and emotions ([13], [36]), CBT is effective in overcoming various psychological problems. In addition, they also stated that CBT works quickly and can be accounted for even though it is done in a short time. This therapy is believed that every individual can change himself for the better by overcoming his problems ([37]).

Cognitive behavior therapy (CBT) is an approach that has an influence on the cognitive therapy and behavior therapy approaches. Therefore, CBT is a combination of approaches in psychotherapy, namely cognitive therapy and behavior therapy ([38], [39]). So that the steps taken by cognitive therapy and behavior therapy are in the implementation of CBT. The characteristics of CBT that not only emphasize changes in cognitive understanding but provide training in behavior in a better direction is considered an appropriate counseling approach to be applied to adolescents with ADHD. The effectiveness of behavior change can occur when followed by a person's cognitive changes. When an individual interprets a situation, the individual's perception of "what he thinks" will affect "what is felt" and "what he does". Therefore, a person's behavior can be changed by changing how a person perceives the process of the situation ([40]). In this study, CBT was used to reduce hyperactive behavior in adolescents with ADHD.

Various techniques in cognitive modification can be done to change a person's behavior, including self-instruction training, attribution retraining, thought stopping, problem-solving, and cognitive restructuring ([41]). Meanwhile, techniques in behavior modification include social skills training, self-monitoring, behavioral testing, token giving, visualization, hypnosis, and goal setting ([42], [43]). Modification of CBT is effective for dealing with psychological problems of children and adolescents, such as impulsivity, hyperactivity, angry emotions, social skills, depression, anxiety, and low levels of self-confidence. 
Several studies have suggested that psychological support begins at the time of diagnosis, for adolescents with ADHD through a process of adjustment coming to accept and understand the results of their diagnosis and the impact of the disorder on their lives ([28]). Psychological care can then shift to a focus on treating coexisting psychiatric problems, psychological problems, and skill deficits ([44]). The goal is to help adolescents with ADHD develop the structure of everyday life and improve the skills of interpersonal so that they can function much better and optimize their potential. Indeed, there is strong evidence to reduce the problem of psychiatric and psychological associated with ADHD. Other forms of psychotherapy such as counseling or therapy-based psychotherapies are assumed to have a role in helping some people to know and understand how the better of ADHD that has affected their personal and emotional life ([45]).

Cognition coaching interventions in adolescents with ADHD to support practicing newly learned skills daily have been used as an adjunct to cognitive cohort programs for adolescents with ADHD ([46]). Therapeutic strategies for adolescent ADHD are the same as those used in childhood. However, some important differences need to be taken into account. Several psychological therapies are applied to ADHD in adolescents and some of them claim to benefit from this therapy. Formal studies of the effectiveness of CBT and psychotherapy have not been widely conducted, but many adolescents with ADHD report that they benefit from this approach ([36]).

From some of these explanations, it can be concluded that adolescents with ADHD need serious handling to reduce their hyperactive behavior which can affect all aspects of their lives. Based on these problems, a study aimed at reducing adolescent hyperactivity with ADHD will be carried out and research is conducted to apply CBT to reduce adolescent ADHD hyperactive behavior in one of the Inclusive Junior High Schools in Indonesia. Based on the previous explanations, the problem in this study could be formulated as follows:

a. Does the implementation of CBT affect the reduction of hyperactive behavior of adolescents with ADHD in Inclusive Junior High Schools?

b. Is the implementation of CBT effective in reducing hyperactive behavior of adolescents with ADHD in Inclusive Junior High Schools?

\section{$2 \quad$ Method}

Research design is a basic framework for carrying out research activities. The clarity of the design can affect the validity of the data and the level of confidence in the research results. In this study, the design used was the case study with one group pretest post-test design, which was an experiment that was carried out in one group without using a control or a comparison group. The sample used in this study was not random. This was due to differences in the characteristics of each subject, in this case, adolescents with ADHD. 
In assessing the effectiveness of CBT to reduce hyperactive behavior in adolescents with ADHD, the following guidelines are used, CBT is said to be effective if it can reduce hyperactive behavior in the range (from the results of the Vanderbilt ADHD Rating Scale scoring). The effective result score should be more than $20 \%$ reduces and it is said to be ineffective if there is a decrease in hyperactive behavior between $0-19 \%$ (from the scoring results of the Vanderbilt ADHD Rating Scale which is adopted into the Indonesian language and culture).

The statistical data analysis technique used is non-parametric statistics with quantitative data and the number of research subjects is small who are three subjects. And descriptive statistical techniques used consisted of averages and percentages to determine the effectiveness of CBT in reducing hyperactive behavior of adolescents with ADHD.

The intervention was composed of a session of pre-intervention (Anamnestic), three sessions of intervention, and a session after the intervention. The time used was five meeting sessions with a time allocation of $2 \times 30$ minutes for each meeting Researchers determine the number and duration of interventions based on the goal that was about to be achieved by the subject of research. The stages of implementing the intervention are shown in Figure 1.

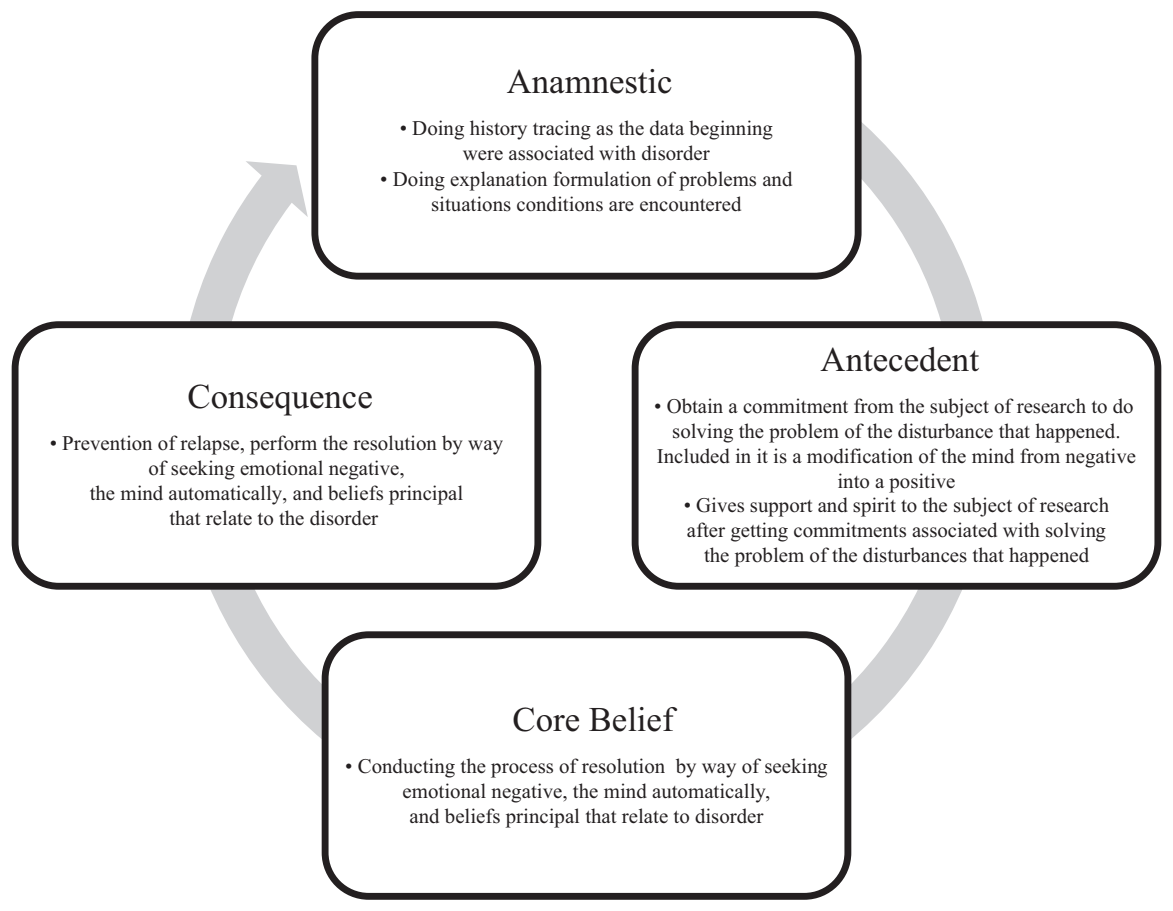

Fig. 1. Description of the intervention implementation

The subjects in this research were defined their gender, IQ level and personal characteristics, see in Table 1. 
Table 1. Subjects characteristics

\begin{tabular}{|l|l|l|l|l|l|}
\hline & ALY & F & 13 & Low (77) & $\begin{array}{l}\text { Characteristics } \\
\text { - Enjoys activities that require physical activity. } \\
\text { - There is a tendency to often act unplanned. Using body gestures. } \\
\text { Unable to sit still for long periods of time. } \\
\text { - Likes to talk, discuss, and explain things at length. } \\
\text { - Concentration is easily broken when the situation is rowdy. }\end{array}$ \\
\hline 1 & KAS & M & 16 & High (110) & $\begin{array}{l}\text { - Avoiding direct eye contact } \\
\text { - The same movements or activities over and over again } \\
\text { - Late physical growth or speech } \\
\text { - Very slow in mastering an everyday language, repeating only a } \\
\text { few words or making meaningless sounds as if he has his own } \\
\text { world so it is difficult to interact with other people }\end{array}$ \\
\hline 3 & LCY & F & 15 & Low (71) & $\begin{array}{l}\text { - Often shy away from reading and writing assignments } \\
\text { - There are no physical abnormalities and low self-adjustment } \\
\text { - Limited memory (not good) } \\
\text { Difficult to grasp abstract concepts } \\
\text { - Slow at work } \\
\text { - Having trouble can organize itself (disorganized, frivolous, } \\
\text { without concept). His belongings were often scattered } \\
\text { irregularly. }\end{array}$ \\
\hline
\end{tabular}

\section{$3 \quad$ Findings}

This study was preceded by the administration of the form of pre-test or by using the instrument test called the Vanderbilt ADHD Rating Scale which has been in the validation and published by the Child Study Center, Department of Pediatrics, University of Oklahoma Health Sciences Center to all selected research subjects ([47]).

This pre-test was carried out to determine the score/level of hyperactivity of the research subject before being given treatment or intervention, whereas the post-test aims to determine the level of quantity and quality of hyperactive behavior in research subjects after being given intervention in the form of the implementation of CBT.

The types of behavior that were measured include;

1) Combined-type of inattentive behavior (impaired concentration of attention) and hyperactivity

2) Inattentive type (impaired concentration of attention)

3) Impulsive type (interference on controlling oneself)

In the following sections, the results of the pre-test and post-test will be explained in detail for each type of behavior. A Post-test was done after the last intervention. A Posttest was conducted to determine changes in the degree of combined type behavior score in adolescents with ADHD after being given intervention in the form of the implementation of CBT. Tests that were used in the post-test were an instrument that was similar to the pre-test. It was done to measure how significant the change difference of score on behavior regarding the measurement tools namely: (1) combined type, (2) inattentive 
type, and (3) impulsive and hyperactivity type in adolescents with ADHD time before and after a given intervention in the form of implementation of the CBT. The results of the post-test scores can be seen in the following table (Table 2).

Table 2. Recapitulation of pre-test and post-test results after the implementation of CBT

\begin{tabular}{|l|c|c|c|c|c|c|c|c|c|c|}
\hline \multirow{2}{*}{ No } & \multirow{2}{*}{ Subject } & \multicolumn{3}{|c|}{ Combined Type } & \multicolumn{3}{c|}{ Inattentive } & \multicolumn{3}{|c|}{$\begin{array}{c}\text { Impulsive } \\
\text { and Hyperactive }\end{array}$} \\
\cline { 3 - 11 } & & $\begin{array}{c}\text { Pre- } \\
\text { test }\end{array}$ & $\begin{array}{c}\text { Post- } \\
\text { test }\end{array}$ & Reduction & $\begin{array}{c}\text { Pre- } \\
\text { test }\end{array}$ & $\begin{array}{c}\text { Post- } \\
\text { test }\end{array}$ & Reduction & $\begin{array}{c}\text { Pre- } \\
\text { test }\end{array}$ & $\begin{array}{c}\text { Post- } \\
\text { test }\end{array}$ & Reduction \\
\hline 1 & ALY & 76 & 48 & $63 \%$ & 51 & 30 & $59 \%$ & 58 & 30 & $52 \%$ \\
\hline 2 & KAS & 86 & 55 & $64 \%$ & 61 & 33 & $54 \%$ & 63 & 33 & $52 \%$ \\
\hline 3 & LCY & 93 & 64 & $69 \%$ & 66 & 40 & $61 \%$ & 67 & 34 & $51 \%$ \\
\hline
\end{tabular}

On the whole, the subjects of the research were very active following the session intervention. After the intervention, the researchers resume the condition of the antecedent and the core belief that appears in the subject of research that produces the response hyperactivity that should be reduced or controlled as in Table 3.

Having found the condition of the antecedent and the core belief that appears, then through the application of CBT, the researchers intend to change and reconstruct the core belief that is negative to the target core belief which is positive.

Table 3. Antecedent, core belief and target core belief that appears in each research subject

\begin{tabular}{|l|l|l|l|l|l|}
\hline No & $\begin{array}{l}\text { Subject } \\
\text { Name }\end{array}$ & \multicolumn{1}{|c|}{ Antecedent } & \multicolumn{1}{|c|}{ Core Belief } & Conditions Arising & \multicolumn{1}{|c|}{ Target Core Belief } \\
\hline 1 & ALY & $\begin{array}{l}\text { Social } \\
\text { environmental } \\
\text { intimidation }\end{array}$ & $\begin{array}{l}\text { 'I'm stupid' } \\
\text { 'I'm naughty' } \\
\text { 'all bad people' }\end{array}$ & $\begin{array}{l}\text { Beating yourself } \\
\text { alone } \\
\text { Hit other people }\end{array}$ & $\begin{array}{l}\text { 'I'm smart' } \\
\text { 'I'm a good boy' } \\
\text { 'All people care about } \\
\text { me'' }\end{array}$ \\
\hline 2 & CASH & $\begin{array}{l}\text { Radio and } \\
\text { Internet }\end{array}$ & $\begin{array}{l}\text { 'I like radio' } \\
\text { 'I like the internet' } \\
\text { 'Every time I had } \\
\text { to use the radio } \\
\text { and the Internet' }\end{array}$ & $\begin{array}{l}\text { (If restricted) } \\
\text { Banging his chest } \\
\text { Biting his hand }\end{array}$ & $\begin{array}{l}\text { 'I love radio and the } \\
\text { internet, but I'm more } \\
\text { like learning' } \\
\text { 'I have to learn first } \\
\text { advance, now I } \\
\text { could use the radio and } \\
\text { the Internet' }\end{array}$ \\
\hline 3 & LCY & Hand Phone & $\begin{array}{l}\text { 'This is my } \\
\text { favourite thing' } \\
\text { 'I like playing } \\
\text { handphone' }\end{array}$ & $\begin{array}{l}\text { (If restricted) } \\
\text { Screaming Jumping } \\
\text { up and down Jog on } \\
\text { the outside of class }\end{array}$ & $\begin{array}{l}\text { 'I like a book more than a } \\
\text { cell phone' } \\
\text { 'I would rather study than } \\
\text { play cell phone' }\end{array}$ \\
\hline
\end{tabular}

\section{Discussion}

Cognitive Behaviour Therapy (CBT) applied in this study aims to reduce hyperactive behavior in adolescents with ADHD. The implementation of CBT is different from other studies which have different research objectives. The implementation of CBT in this study is closely related to cognitive development in each research subject, 
this is because CBT intends to change wrong beliefs in individuals with ADHD so as to produce wrong behavioral responses. For more details, the following is an analysis of activities based on the stages of intervention given by researchers according to the stages of CBT intervention, namely:

\subsection{Antecedent identification (trigger factors)}

In the first session, before identifying the trigger, the researchers took the subject of research to evaluate the experience of his life. It was done as a step early to identify the factors that become a trigger condition of hyperactivity on the research subject. The subject ALY concluded that become factors trigger (antecedent) a condition of hyperactivity is a neighborhood social intimidation. He mentioned that his neighbors sparked the subject ALY to hit themselves and friends around him. Differently, the subject KAS concluded in accordance with the results of observation and interviewing the parents and teachers, factors that become' trigger condition of hyperactivity is the use of internet and radio are excessive. If the desire ss strong to use the internet and radio are restricted, then the condition of hyperactivity which appears is hurting himself alone with banging the chest itself and gnawed on the hand itself. As for the subject of LCY, factors triggering the condition of hyperactivity that is concluded is the use of means of communication (for mobile phones) is excessive. So that when the use of Mobile Phone restricted, then the thing that appears is an inconvenience subject LCY with the advent of the behavior of jumping without stopping, screaming with loud and take a walk outside his class.

\subsection{Belief identification of the subject against the trigger factors}

Identifying the research subjects' beliefs about the triggering factors for a condition was carried out in the second and third sessions. In this session, the researcher/therapist will:

a. Do face to face with research subjects. The subject of research is required to tell back on anything that has been experienced and thought or felt. The therapist makes in-queries based on the story of the research subject. Activity is aimed to explore the core belief (faith basis) the subject of research on factors that trigger a state of hyperactivity.

b. Conducting the process of resolution, which is seeking the emotions negative and beliefs principal that relate to disorder, conduct discussions, and evaluating the entire incident that happened. Therapists provide evidence regarding the system of beliefs and the mind automatically is very closely related to emotions and behavior, by the way, refused mind negative is smooth and offer thoughts positive as an alternative to proven joint.

c. The therapist obtains a commitment from the subject of research in terms of the provision of reinforcement (reward) and punishment which is associated with the thoughts that arise from the subject of research. The therapist also needs to clarify the relationship between the mind of a negative result in punishment and the mind positive which resulted in the reward. 
At the end of this session, the therapist provides an understanding and explanation of the negative thoughts or core beliefs that arise by between the researcher and the research subject that to change the core belief that appears in the next intervention session by selecting rewards and punishments that are agreed upon by the therapist and the research subject.

\subsection{Analyzing the consequences that arise}

After identifying the beliefs of the participants that impact the condition of hyperactivity that appears. The steps which were performed at these sessions are:

d. Provide support and passion associated with the progress that is achieved by the subject of research.

e. Remind the focus of therapy on participants, which focuses on changing the hyperactive behavior of research subjects from negative to more positive.

f. Prevention of relapse, perform the resolution by way of seeking emotional negative, the mind automatically, and beliefs principal that relate to the disorder.

g. Clarify general knowledge about the term relapse to ensure that the research subject understands its meaning and is able to choose the action that must be taken.

h. Obtain a commitment from the subject of the research to be actively shaping the mind-feeling things for the positive in every problem faced.

After the therapist analyses the core beliefs found in each research subject, the researcher resolves negative thoughts on each of the research subjects by providing positive alternative thoughts in the form of target core beliefs which are different for each subject.

\section{Conclusion}

Based on the results of the analysis and discussion, it can be concluded that: There is an effect of the implementation of Cognitive behavior therapy (CBT) in reducing hyperactive behavior among adolescents with Attention Deficit and Hyperactive Disorder (ADHD) at Inclusive Junior High Schools in Indonesia. The number of differences between the pre-test and post-test results after the implementation of CBT in 3 adolescent subjects with ADHD was;

- 75 points in the inattentive behavior

- 97 points on the hyperactive type of behavior

- 88 points on the combined type of behavior

\section{References}

[1] R. V. Kail and J. C. Cavanaugh, Human development: A life-span view. Cengage Learning, 2018.

[2] J. Valsiner, G. Marsico, N. Chaudhary, T. Sato, and V. Dazzani, "Psychology as the science of human being," Yokohama Manif., pp. 129-147, 2016. https://doi.org/10.1007/ 978- 3-319-21094-0 
[3] D. Villani et al., "Adolescents' beliefs about peers' engagement in an online self-harm challenge: exploring the role of individual characteristics through a latent class analysis," Cyberpsychology, Behav. Soc. Netw., vol. 22, no. 11, pp. 684-691, 2019. https://doi.org/ 10.1089/cyber.2019.0002

[4] J. Burén and C. Lunde, "Sexting among adolescents: A nuanced and gendered online challenge for young people," Comput. Human Behav., vol. 85, pp. 210-217, 2018. https://doi. org/10.1016/j.chb.2018.02.003

[5] G. Tiwari and R. Galundia, "Academic backwardness among rural adolescents: Challenge for society,” Int. J., vol. 4, no. 3, pp. 438-443, 2016.

[6] A. Cook et al., "Complex trauma in children and adolescents," Psychiatr. Ann., vol. 35, no. 5, pp. 390-398, 2017. https://doi.org/10.3928/00485713-20050501-05

[7] B. Revathi, A. J. Priya, and G. Devi, "Awareness about attention-deficit hyperactivity disorder among teenagers," Drug Invent. Today, vol. 10, no. 11, 2018.

[8] J. H. Barnett, "Three evidence-based strategies that support social skills and play among young children with autism spectrum disorders," Early Child. Educ. J., vol. 46, no. 6, pp. 665-672, 2018. https://doi.org/10.1007/s10643-018-0911-0

[9] L. Reale and M. Bonati, "ADHD prevalence estimates in Italian children and adolescents: a methodological issue,” Ital. J. Pediatr., vol. 44, no. 1, p. 108, 2018. https://doi.org/10.1186/ s13052-018-0545-2

[10] R. A. Barkley, Taking charge of ADHD: The complete, authoritative guide for parents. Guilford press, 2020

[11] K. Sayal, V. Prasad, D. Daley, T. Ford, and D. Coghill, "ADHD in children and young people: prevalence, care pathways, and service provision," The Lancet Psychiatry, vol. 5, no. 2, pp. 175-186, 2018. https://doi.org/10.1016/S2215-0366(17)30167-0

[12] T. Peasgood et al., "The impact of ADHD on the health and well-being of ADHD children and their siblings," Eur. Child Adolesc. Psychiatry, vol. 25, no. 11, pp. 1217-1231, 2016. https://doi.org/10.1007/s00787-016-0841-6

[13] J. R. Ramsay, “'Turning Intentions Into Actions' CBT for Adult ADHD Focused on Implementation," Clin. Case Stud., vol. 15, no. 3, pp. 179-197, 2016. https://doi.org/10.1177/ 1534650115611483

[14] C. Gawrilow, G. Stadler, N. Langguth, A. Naumann, and A. Boeck, "Physical activity, affect, and cognition in children with symptoms of ADHD," J. Atten. Disord., vol. 20, no. 2, pp. 151-162, 2016. https://doi.org/10.1177/1087054713493318

[15] B. Mörstedt, S. Corbisiero, H. Bitto, and R.-D. Stieglitz, "Emotional symptoms and their contribution to functional impairment in adults with attention-deficit/hyperactivity disorder," ADHD Atten. Deficit Hyperact. Disord., vol. 8, no. 1, pp. 21-33, 2016. https://doi.org/ 10.1007/s12402-015-0181-2

[16] M. Wang, P. A. Kirschner, and S. M. Bridges, "Computer-based learning environments for deep learning in inquiry and problem-solving contexts," in Proceedings of the 12th International Conference of the Learning Sciences (ICLS), 2016.

[17] H.-M. Vasiliadis et al., "Temporal trends in the prevalence and incidence of diagnosed ADHD in children and young adults between 1999 and 2012 in Canada: a data linkage study," Can. J. Psychiatry, vol. 62, no. 12, pp. 818-826, 2017. https://doi.org/10.1177/ $\underline{0706743717714468}$

[18] M. Alzyoudi, A. Sartawi, and O. Almuhiri, "The impact of video modelling on improving social skills in children with autism,” Br. J. Spec. Educ., vol. 42, no. 1, pp. 53-68, 2015. https://doi.org/10.1111/1467-8578.12057

[19] M. Tandon, R. Tillman, A. Agrawal, and J. Luby, "Trajectories of ADHD severity over 10 years from childhood into adulthood," ADHD Atten. Deficit Hyperact. Disord., vol. 8, no. 3, pp. 121-130, 2016. https://doi.org/10.1007/s12402-016-0191-8 
[20] B. T. Guelzow, F. Loya, and S. P. Hinshaw, "How persistent is ADHD into adulthood? Informant report and diagnostic thresholds in a female sample," J. Abnorm. Child Psychol., vol. 45, no. 2, pp. 301-312, 2017. https://doi.org/10.1007/s10802-016-0174-4

[21] C. L. Frank and V. Zascavage, "Assessing the Included Classroom,” Incl. Educ. A Syst. Perspect., p. 61, 2020.

[22] S. S. Sajadi, "A Tentative Model of the Link between Constructivist Learning Approach and Attention-Deficit Hyperactivity Disorder,” Int. J. Emerg. Technol. Learn., vol. 10, no. 5, 2015. https://doi.org/10.3991/ijet.v10i5.4733

[23] R. Fried, C. Petty, S. V. Faraone, L. L. Hyder, H. Day, and J. Biederman, "Is ADHD a risk factor for high school dropout? A controlled study," J. Atten. Disord., vol. 20, no. 5, pp. 383-389, 2016. https://doi.org/10.1177/1087054712473180

[24] K. van Emmerik-van Oortmerssen et al., "Prediction of drop-out and outcome in integrated cognitive behavioral therapy for ADHD and SUD: Results from a randomized clinical trial," Addict. Behav., vol. 103, p. 106228, 2020. https://doi.org/10.1016/j.addbeh.2019.106228

[25] H. McCarthy et al., "Childhood-diagnosed ADHD, symptom progression, and reversal learning in adulthood," J. Atten. Disord., vol. 22, no. 6, pp. 561-570, 2018. https://doi. org $/ 10.1177 / 1087054716661233$

[26] L. A. Adler, S. V. Faraone, T. J. Spencer, P. Berglund, S. Alperin, and R. C. Kessler, "The structure of adult ADHD," Int. J. Methods Psychiatr. Res., vol. 26, no. 1, p. e1555, 2017. https://doi.org/10.1002/mpr.1555

[27] N. Ringer, "Living with ADHD: A meta-synthesis review of qualitative research on children's experiences and understanding of their ADHD," Int. J. Disabil. Dev. Educ., vol. 67, no. 2, pp. 208-224, 2020. https://doi.org/10.1080/1034912X.2019.1596226

[28] M. A. Jarrett, J. C. Wolff, T. E. Davis III, M. J. Cowart, and T. H. Ollendick, "Characteristics of children with ADHD and comorbid anxiety," J. Atten. Disord., vol. 20, no. 7, pp. 636-644, 2016. https://doi.org/10.1177/1087054712452914

[29] M. Giacobini, E. Medin, E. Ahnemark, L. J. Russo, and P. Carlqvist, "Prevalence, patient characteristics, and pharmacological treatment of children, adolescents, and adults diagnosed with ADHD in Sweden,” J. Atten. Disord., vol. 22, no. 1, pp. 3-13, 2018. https://doi. org/10.1177/1087054714554617

[30] W. Hayashi et al., "Clinical Characteristics of Women with ADHD in Japan," Neuropsychiatr. Dis. Treat., vol. 15, p. 3367, 2019. https://doi.org/10.2147/NDT.S232565

[31] A. Drigas and A. Tourimpampa, "Processes and ICT Tools for ADHD Assessment, Intervention and Attention Training.," Int. J. Emerg. Technol. Learn., vol. 9, no. 6, 2014. https:// doi.org/10.3991/ijet.v9i6.4001

[32] L. Bakola, N. Rizos, and A. Drigas, "ICTs for emotional and social skills development for children with ADHD and ASD co-existence," Int. J. Emerg. Technol. Learn., vol. 14, no. 05, pp. 122-131, 2019. https://doi.org/10.3991/ijet.v14i05.9430

[33] L. Romo et al., "Cognitive distortions and ADHD in pathological gambling: A national longitudinal case-control cohort study,” J. Behav. Addict., vol. 5, no. 4, pp. 649-657, 2016. https://doi.org/10.1556/2006.5.2016.070

[34] P. A. Aduen, T. N. Day, M. J. Kofler, S. L. Harmon, E. L. Wells, and D. E. Sarver, "Social problems in ADHD: Is it a skills acquisition or performance problem?" J. Psychopathol. Behav. Assess., vol. 40, no. 3, pp. 440-451, 2018. https://doi.org/10.1007/s10862-018-9649-7

[35] M.-R. Pan, F. Huang, M.-J. Zhao, Y.-F. Wang, Y.-F. Wang, and Q.-J. Qian, “A comparison of efficacy between cognitive behavioral therapy (CBT) and CBT combined with medication in adults with attention-deficit/hyperactivity disorder (ADHD)," Psychiatry Res., vol. 279, pp. 23-33, 2019. https://doi.org/10.1016/j.psychres.2019.06.040

[36] P. Cole et al., "CBT/DBT skills training for adults with attention deficit hyperactivity disorder (ADHD)," Psychiatr Danub, vol. 28, no. Suppl 1, pp. 103-107, 2016. 
[37] B. Curwen, S. Palmer, and P. Ruddell, Brief cognitive behaviour therapy. Sage, 2018. https:// doi.org/10.4135/9781526447661

[38] G. Haddock et al., "Delivery of cognitive-behaviour therapy for psychosis: a service user preference trial," J. Ment. Heal., vol. 27, no. 4, pp. 336-344, 2018. https://doi.org/10.1080/ 09638237.2017.1417549

[39] S. Rathod, P. Phiri, and F. Naeem, "An evidence-based framework to culturally adapt cognitive behaviour therapy,” Cogn. Behav. Ther., vol. 12, 2019. https://doi.org/10.1017/ $\underline{\text { S1754470X18000247 }}$

[40] V. MacGill, "Reframing Cognitive Behaviour Theory from a Systems Perspective," Syst. Pract. Action Res., vol. 31, no. 5, pp. 495-507, 2018. https://doi.org/10.1007/s11213-017$\underline{9440-9}$

[41] N. G. Medina, "Cognitive modification in students with Reading problems and ADHD- CT," Rev. Puertorriquena Psicol., vol. 29, no. 2, p. 302, 2018.

[42] S. Whitney and G. A. Martin, "Adventure Games as Deaf Education Tools: Action Research Results,” J. Bord. Educ. Res., vol. 6, no. 1, 2013.

[43] D. H. Solt, "Parents' Perspectives: How They Use Behaviour Modification Techniques with Toddlers Aged 1-3," 2017.

[44] J. D. Wilson, Student learning in higher education. Routledge, 2018. https://doi.org/10.4324/ 9780429445569

[45] A. Robinson, C. Simpson, and B. L. Hott, "The effects of child-centered play therapy on the behavioural performance of three first grade students with ADHD.," Int. J. Play Ther., vol. 26, no. 2, p. 73, 2017. https://doi.org/10.1037/pla0000047

[46] L. K. Koegel, R. L. Koegel, R. M. Fredeen, and G. W. Gengoux, "Naturalistic behavioural approaches to treatment," Autism Spectr. Disord. infants' toddlers Diagnosis, assessment, Treat., vol. 207242, 2008.

[47] Ogg J. A., Fefer S. A. (2011) Vanderbilt Teacher Assessment Scale. In: Goldstein S., Naglieri J.A. (eds) Encyclopedia of Child behavior and Development. Springer, Boston, MA. https://doi.org/10.1007/978-0-387-79061-9 3006

\section{Authors}

Khofidotur Rofiah is a PhD student in Uniwersytet Pedagogiczny im. Komisji Edukacji Narodowej w Krakowie, Poland. Also, she is a lecturer at the Special Education Department, Faculty of Education, Universitas Negeri Surabaya, Indonesia. She has published several papers, and has interests in Inclusive Education, students with behavioural issue, students with deaf, and behaviour modification.

Joanna Kossewska is a professor at the Institute of Special Education, Uniwersytet Pedagogiczny im. Komisji Edukacji Narodowej w Krakowie, Poland. She has published several papers, and has interests in psychology of children with disabilities.

Muhammad Nurul Ashar is a lecturer at the Special Education Department, Faculty of Education, Universitas Negeri Surabaya, Indonesia. He has published several papers, and has interests in students with ASD and behaviour modification.

Article submitted 2021-08-26. Resubmitted 2021-10-05. Final acceptance 2021-10-08. Final version published as submitted by the authors. 